\title{
The origin and significance of short-term variability of semi- volatile contaminants in air
}

\author{
SUPPORTING INFORMATION
}

Matthew MacLeod, Martin Scheringer, Heike Podey, Kevin C. Jones and Konrad Hungerbühler

\begin{tabular}{ll}
\hline & \multicolumn{1}{c}{ Contents } \\
S-2 & 1. Diel Model Structure and Parameterization \\
S-9 & $\begin{array}{l}\text { 2. Environmental Conditions During Other Diel Studies of Semi-Volatile Organic } \\
\text { Chemicals in Air }\end{array}$ \\
S-16 & $\begin{array}{l}\text { 3. Additional Model Results for the Case Studies Presented in the Main Text. } \\
\text { S-20 }\end{array}$ \\
\hline
\end{tabular}

Tables

S-3 Table S1: Median values and associated confidence factors for model input parameters used in all model scenarios

Table S2: Geometric mean values and associated confidence factors for model input

S-4 parameters describing local environmental characteristics that are not variable over the diel cycle.

S-5 Table S3: Fitting parameters for sinusoidal forcing functions describing diel variable input parameters to the model and associated confidence factors.

S-8 Table S4: Physico-chemical properties, degradation rate constants and associated confidence factors for selected PCB congeners.

\section{Figures}

S-6 Figure S1: Forcing functions used as model inputs for windspeed in the lower air compartments compared with observed windspeed recorded at the sampling site.

Figure S2: Comparison of three-month average PCB concentrations in air at Hazelrigg,

S-7 UK during July, August and September, 1995 with the constant background inflow concentration tuned to fit the model to diel measurements data reported by Lee et al.

S-10 Figure S3: Diel variability in temperature and atmospheric mixing height at Marcell Bog, USA In July 1993.

S-11 Figure S4: Diel variability in temperature and atmospheric mixing height at Bloomington, Indiana, USA in September 1994.

S-12 Figure S5: Variability in atmospheric mixing height in central Louisiana during June, 1999 and June 2000.

S-14 Figure S6: Concentration of beta-hexachlorcyclohexane $(\beta-\mathrm{HCH})$ in air, temperature and atmospheric mixing height at Izmir, Turkey in May, 2003.

S-16 Figure S7: Temperature and atmospheric mixing height at Raritan Bay, New Jersey in July, 1998.

S-17 Figure S8: Additional monitoring data and model results for the Hazelrigg, UK case study

S-18 Figure S9: Additional monitoring data and model results for the Finokalia, Greece case study

S-19 Figure S10: Additional monitoring data and model results for the Chicago, USA case study 


\section{Diel Model Structure and Parameterization}

\subsection{Monte Carlo Uncertainty Analysis}

Uncertainty in model output due to uncertainty and variability in model input values has been assessed for all model runs using Monte Carlo uncertainty analysis and 1000 discrete realizations of the model. The range of possible values of each model input parameter was specified as a confidence factor $(\mathrm{CF})$ that defines the extent to which a given Monte Carlo input value, $X$, deviates from the geometric mean input value, $\mu,(1)$;

$$
\text { probability }\left\{\frac{\mu}{C F}<X<C F \times \mu\right\}=0.95 \text {. }
$$

The use of confidence factors to estimate uncertainty and variability in model inputs implicitly assumes log-normal distributions of possible values.

\subsection{Environmental Parameterization}

The geometric mean of most model input parameters is set at default values recommended by Mackay (2). Table S1 shows input parameters and associated confidence factors that were common to all three modeling scenarios described in the main text and that were held constant during diel model simulations. In most cases these values have also been used in previous applications of similar mass balance models (3-6). 
Table S1: Median values and associated confidence factors for model input parameters used in all model scenarios (MTC $=$ mass transfer coefficient).

\begin{tabular}{|c|c|c|c|}
\hline Subcompartment volume fractions (dimensionless) & Median & CF & Reference \\
\hline Particles in upper air & $2 \mathrm{E}-11$ & 3 & a \\
\hline Particles in lower air & $2 \mathrm{E}-11$ & 3 & a \\
\hline Particles in fresh water & 0.000005 & 3 & a \\
\hline Fish in fresh water & 0.000001 & 3 & a \\
\hline Particles in coastal water & 0.000005 & 3 & a \\
\hline Fish in coastal water & 0.000001 & 3 & a \\
\hline Air in soil & 0.2 & 1.1 & a \\
\hline Water in soil & 0.3 & 1.1 & a \\
\hline Soil solids & 0.5 & 1.1 & a \\
\hline Sediment pore water & 0.7 & 1.1 & a \\
\hline Sediment solids & 0.3 & 1.1 & a \\
\hline Water in vegetation & 0.75 & 1.1 & b \\
\hline Pseudo-octanol in vegetation biomass & 0.01 & 3 & b \\
\hline \multicolumn{4}{|l|}{ Density of subcompartments $\left(\mathrm{kg} / \mathrm{m}^{3}\right)$} \\
\hline Air particles & 2400 & 1.5 & $a$ \\
\hline Water & 1000 & 1.05 & a \\
\hline Water particles & 2400 & 1.5 & a \\
\hline Fresh water biota & 1000 & 1.05 & a \\
\hline Soil solids & 2400 & 1.5 & a \\
\hline Sediment solids & 2400 & 1.5 & a \\
\hline Coastal water biota & 1000 & 1.05 & a \\
\hline Vegetation flesh & 600 & 1.5 & b \\
\hline \multicolumn{4}{|l|}{ Organic carbon fraction (dimensionless) } \\
\hline Particles in fresh water & 0.2 & 1.5 & $a$ \\
\hline Particles in coastal water & 0.2 & 1.5 & a \\
\hline Soil solids & 0.02 & 1.5 & a \\
\hline Sediment solids & 0.04 & 1.5 & a \\
\hline \multicolumn{4}{|l|}{ Transport velocity parameters ( $\mathrm{m} / \mathrm{h}$ ) } \\
\hline 1 air side air-fresh water M̈TC & 3 & 3 & a \\
\hline 2 water side air-fresh water MTC & 0.03 & 3 & a \\
\hline 3 rain rate & 0 & 3 & c \\
\hline 4 aerosol depositon & 10.8 & 3 & a \\
\hline 5 soil air phase diffustion MTC & 0.04 & 3 & a \\
\hline 6 soil water phase diffusion MTC & 0.00001 & 3 & a \\
\hline 7 soil air boundary layer MTC & 1 & 3 & a \\
\hline 8 sediment-water diffusion MTC & 0.0001 & 3 & a \\
\hline 9 sediment deposition & $5 \mathrm{E}-07$ & 3 & a \\
\hline 10 sediment resuspension & 2E-07 & 3 & a \\
\hline 11 soil water runoff & 4.32E-05 & 3 & a \\
\hline 12 soil solids runoff & $2.16 \mathrm{E}-08$ & 3 & a \\
\hline 13 sediment burial & 3E-07 & 3 & a \\
\hline 14 diffusion to stratosphere & 0.01 & 3 & a \\
\hline 15 leaching from soil & 0.000011 & 3 & a \\
\hline 16 Soil solids convection rate & 4.54E-07 & 3 & $d$ \\
\hline 17 air side air-veg. MTC & 9 & 3 & $b$ \\
\hline 18 veg. water uptake velocity & 0.0001 & 3 & $b$ \\
\hline 19 upper-lower air mixing MTC & 52.5 & 10 & e \\
\hline 20 air side air-coastal water MTC & 3 & 3 & a \\
\hline 21 water side air-coastal water MTC & 0.03 & 3 & a \\
\hline \multicolumn{4}{|l|}{ Vegetation growth dilution } \\
\hline Average vegetation cycle (days) & 240 & 1.1 & $\mathrm{~b}$ \\
\hline
\end{tabular}

(a) - (2), (b) - (7), (c) - No rain was reported during sampling at any of the sites, (d) - (8), (e) Selected to simulate complete mixing between upper and lower atmosphere layers at the beginning of diel model runs. 
Table S2 shows model input parameters that describe the local characteristics at the three sampling sites described in the main text. Parameters shown in Table S2 are held constant during diel model simulations.

Table S2: Geometric mean values and associated confidence factors for model input parameters describing local environmental characteristics that are not variable over the diel cycle.

\begin{tabular}{|c|c|c|c|c|}
\hline Region dimensions & Hazelrigg, UK & Chicago, USA & $\begin{array}{c}\text { Finokalia, } \\
\text { Greece }\end{array}$ & CF \\
\hline Total surface area $\left(\mathrm{km}^{2}\right)$ & 100000 & 100000 & 100000 & 1 \\
\hline$\%$ Surface covered by fresh water & 0 & 40 & 0 & 1.1 \\
\hline$\%$ Surface covered by coastal water & 0 & 0 & 90 & 1.5 \\
\hline$\%$ Soil covered by vegetation & 80 & 80 & 80 & 1.1 \\
\hline Leaf area index $\left(\mathrm{m}^{2} / \mathrm{m}^{2}\right)$ & 4 & 4 & 4 & 1.5 \\
\hline vegetation mass per square meter $\left(\mathrm{kg} / \mathrm{m}^{2}\right)$ & 1 & 1 & 1 & 1.5 \\
\hline Average lower air compartment height $(\mathrm{km})$ & 0.1 & 0.1 & 0.1 & 1.5 \\
\hline Average upper air compartment height $(\mathrm{km})$ & 0.9 & 1.5 & 0.25 & 1.5 \\
\hline Average fresh water depth $(\mathrm{m})$ & $\mathrm{N} / \mathrm{A}$ & 20 & $\mathrm{~N} / \mathrm{A}$ & 1.5 \\
\hline Average coastal water depth (m) & $\mathrm{N} / \mathrm{A}$ & $\mathrm{N} / \mathrm{A}$ & 100 & 1.5 \\
\hline Average soil depth $(\mathrm{cm})$ & 10 & 10 & 10 & 1.5 \\
\hline Average fresh water sediment depth $(\mathrm{cm})$ & $\mathrm{N} / \mathrm{A}$ & 3 & $\mathrm{~N} / \mathrm{A}$ & 3 \\
\hline
\end{tabular}

Forcing functions used to simulate diel variability in temperature, mixing height and hydroxyl radical concentration are illustrated in Figure 2 in the main text. A forcing function was also applied to vary windspeed through the lower air compartment as described below, however variability in windspeed was not found to be influential in determining variability of PCB concentrations in air in any of the model scenarios. All of the forcing functions are based on the sine function with a 24-hour periodicity, in some cases truncated at maximum or minimum values. Fitting parameters for the forcing functions are average value, amplitude, phase offset and, where required, truncation limits, as shown in Table S3. 
Table S3: Fitting parameters for sinusoidal forcing functions describing diel variable input parameters to the model and associated confidence factors. The phase parameter sets the number of hours after midnight that the first minimum of the sine function occurs. (MTC = mass transfer coefficient).

\begin{tabular}{|c|c|c|c|c|c|c|c|}
\hline Temperature $\left({ }^{\circ} \mathrm{C}\right)$ & Mean Value & CF & Amplitude & $\mathbf{C F}$ & Phase (h) & CF & Truncation Limits \\
\hline Hazelrigg, UK & 25 & 1.1 & 6 & 1.3 & 4 & 1.5 & \\
\hline Chicago, USA & 20 & 1.1 & 5 & 1.3 & 4 & 1.5 & $\mathrm{~N} / \mathrm{A}$ \\
\hline Finokalia, Greece & 25 & 1.1 & 2 & 1.3 & 4 & 1.5 & \\
\hline \multicolumn{8}{|l|}{ Mixing MTC $(\mathrm{m} / \mathrm{h})$} \\
\hline Hazelrigg, UK & 52.5 & 3 & 500 & 1 & 4 & 1.5 & \multirow{3}{*}{$\begin{array}{c}\text { Maximum }=100 \\
\text { Minimum }=0\end{array}$} \\
\hline Chicago, USA & 52.5 & 3 & 500 & 1 & 5 & 1.5 & \\
\hline Finokalia, Greece & 52.5 & 3 & N/A & $\mathrm{N} / \mathrm{A}$ & $\mathrm{N} / \mathrm{A}$ & $\mathrm{N} / \mathrm{A}$ & \\
\hline \multicolumn{8}{|c|}{$[\mathrm{OH}]\left(\mathrm{mol} \mathrm{cm}-3 / 10^{6}\right)$} \\
\hline Hazelrigg, UK & 0.97 & 3 & 0.39 & 1 & 6 & 1.5 & \multirow{3}{*}{$\begin{array}{l}{[\mathrm{OH}]=0 \text { when }} \\
\text { value would be less } \\
\text { than mean value }\end{array}$} \\
\hline Chicago, USA & 3.00 & 3 & 1.22 & 1 & 6 & 1.5 & \\
\hline Finokalia, Greece & 9.75 & 3 & 3.96 & 1 & 6 & 1.5 & \\
\hline \multicolumn{8}{|l|}{ Windspeed $(\mathrm{km} / \mathrm{h})$} \\
\hline Hazelrigg, UK & 6 & 2 & 3 & 1.5 & 6 & 1.5 & \multirow{3}{*}{$\mathrm{N} / \mathrm{A}$} \\
\hline Chicago, USA & 9 & 2 & 4.5 & 1.5 & 6 & 1.5 & \\
\hline Finokalia, Greece & 19 & 2 & 9.5 & 1.5 & 6 & 1.5 & \\
\hline
\end{tabular}

In most cases fitting parameters shown in Table S3 were selected to fit data gathered at or near the sampling sites during sampling, or to fit mixing height data from the NCEP reanalysis of climate data. The forcing function for mixing height shown in Figure 1 is achieved by varying the mass transfer coefficient for mixing between the upper and lower atmospheric layers of the model. The truncated sine functions described in Table S3 have the overall effect of blocking exchange between the two atmospheric layers during the night and allowing rapid mixing over a timescale of less than 1 hour during the day. The mixing height illustrated in Figure 1 is thus determined by the regional parameters specified in Table S2. At Finokalia, where very little variability in mixing height is indicated in the NCEP data, mixing between the two atmospheric layers is rapid over the entire diel period, and the mixing height is $350 \mathrm{~m}$. Forcing functions for hydroxyl radical concentrations in the atmosphere assume 12 hours of daylight by truncating the function when values calculated by the sine function would be lower than the mean value. The amplitude of the truncated sine function is set to 0.406 times the mean, which produces 24-hour average hydroxyl radical concentrations equal to the mean value. 
Forcing functions for windspeed in the lower air compartment are shown in Figure S1 along with windspeed measurements made at the sampling sites during sample collection. In most cases windspeed was reported only as 12 or 24 hour averages.
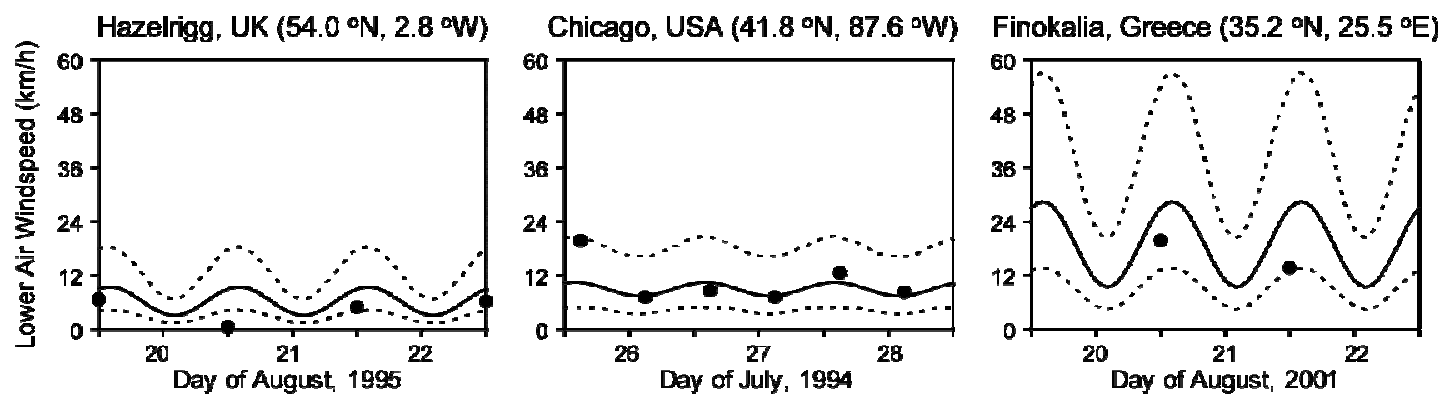

Figure S1: Forcing functions used as model inputs for windspeed in the lower air compartments compared with observed windspeed recorded at the sampling site.

\subsection{Specification of Background Concentrations at Hazelrigg}

As described in the main text, we modeled the PCB source to the Hazelrigg site as a constant inflowing concentration in background air. The inflow concentration was treated as a tunable parameter. The value used in the simulations was selected to give the best possible agreement with observations from the field, however at Hazelrigg a longterm monitoring program was being conducted concurrently with the diel monitoring program during the summer of 1995 and represents an independent dataset that can be compared with the tuned model input. Figure S2 compares the tuned model background concentrations used as input to the model against three-month average concentrations of seven PCB congeners at the Hazelrigg site reported by the Toxic Organic Micro Pollutants (TOMPs) monitoring program (http://www.airquality.co.uk/archive/tomps.php). 


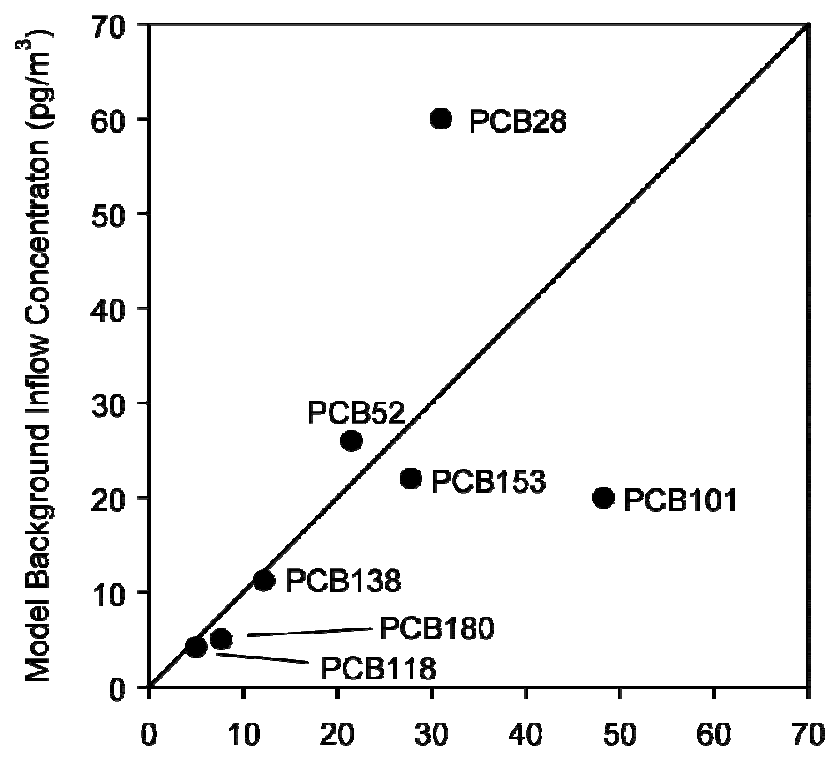

Three-Month Average Concentration July-Sept. $1995\left(\mathrm{pg} / \mathrm{m}^{3}\right)$

Figure S2: Comparison of three-month average PCB concentrations in air at Hazelrigg, UK during July, August and September, 1995 with the constant background inflow concentration tuned to fit the model to diel measurements data reported by Lee et al. (9).

As illustrated in Figure S2, the background inflow concentrations used as input to the model for the Hazelrigg scenario are highly consistent with three-month average concentrations at the site for PCBs 52, 118, 138, 153 and 180. For PCB28 and PCB101 the model input and three month average concentrations are within a factor of 3 , and the discrepancy could be due to episodic variability.

\subsection{Physico-Chemical Properties of PCB Congeners}




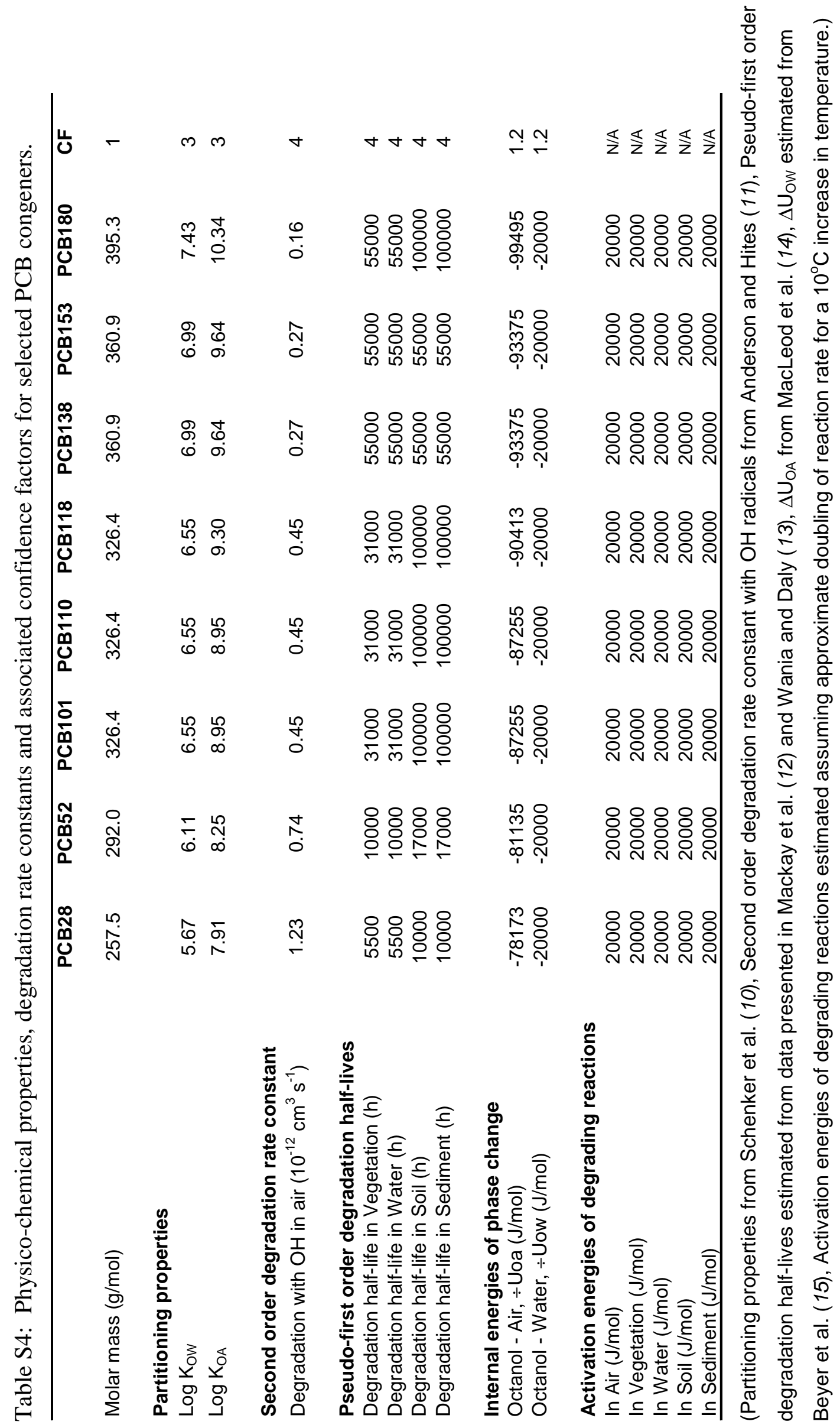


2. Environmental Conditions During Other Diel Studies of Semi-Volatile Organic Chemicals in Air

2.1 Hornbuckle and Eisenreich (16).

Hornbuckle and Eisenreich reported diel variability in total polychlorinated biphenyls and hexachlorobenzene in air measured at the Marcell Bog in Minnesota, USA (16). They report data for four sampling periods, and observed peaks in concentrations in air that corresponded with maximum temperatures during the day. Figure S3 shows temperature data reported in their paper and mixing height at the Marcell Bog from the NCEP reanalysis data during the July 1993 sampling period. The Marcell Bog is remote from any possible sources of polychlorinated biphenyls or hexachlorobenzene, and therefore the source of contamination in the area is transport in air. Conditions at the sampling site and diel patterns of SVOC concentrations in air are therefore analogous to conditions at Hazelrigg, UK in August 1995, as described in the main text. 

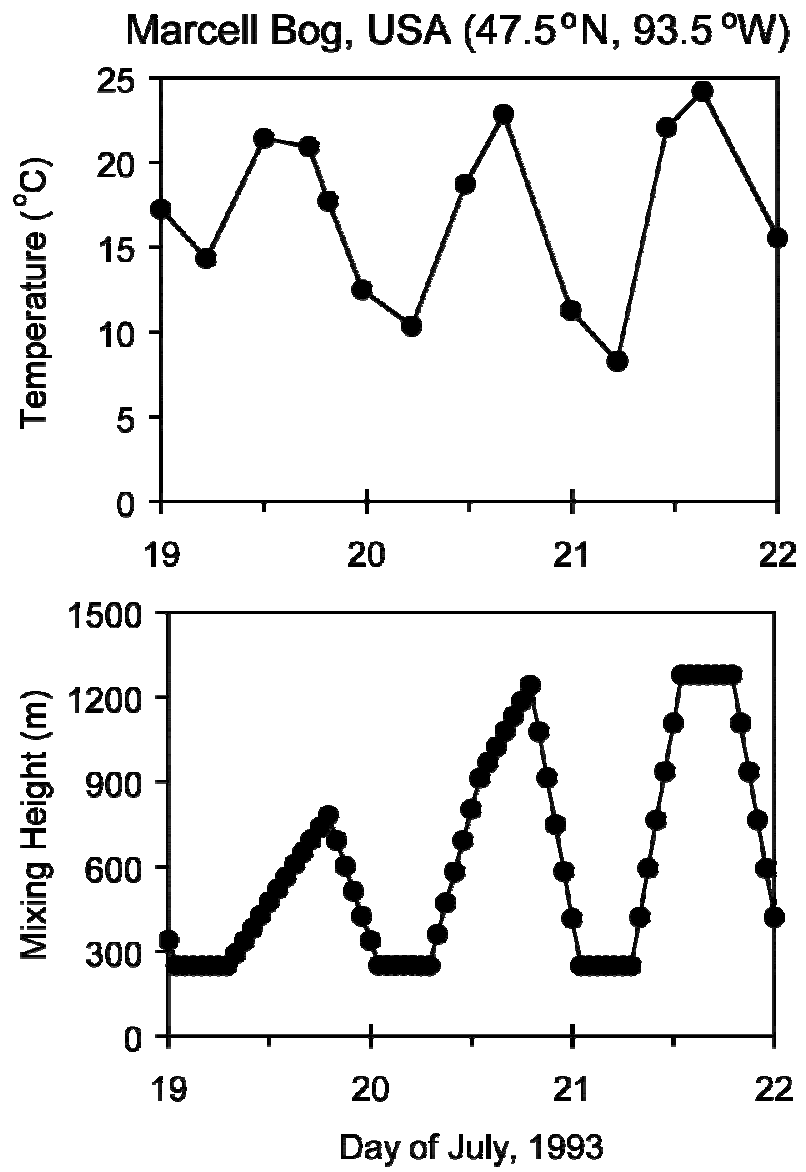

Figure S3: Diel variability in temperature (16) and atmospheric mixing height (17) at Marcell Bog, USA In July 1993.

2.2 Wallace and Hites (18).

Wallace and Hites reported diel variability in total polychlorinated biphenyls and endosulfan in air measured at Bloomington, Indiana, USA (18). They observed peaks in concentrations in air that corresponded with maximum temperatures during the day. Figure S4 shows temperature data reported in their paper and mixing height at Bloomington Indiana from the NCEP reanalysis data during the September 1994 sampling period. The monitoring site is remote from any possible sources of polychlorinated biphenyls or endosulfan, and therefore the source of contamination in the area is transport in air. Conditions at the sampling site and diel patterns of SVOC concentrations in air are therefore analogous to conditions at Hazelrigg, UK in August 1995, as described in the main text. 


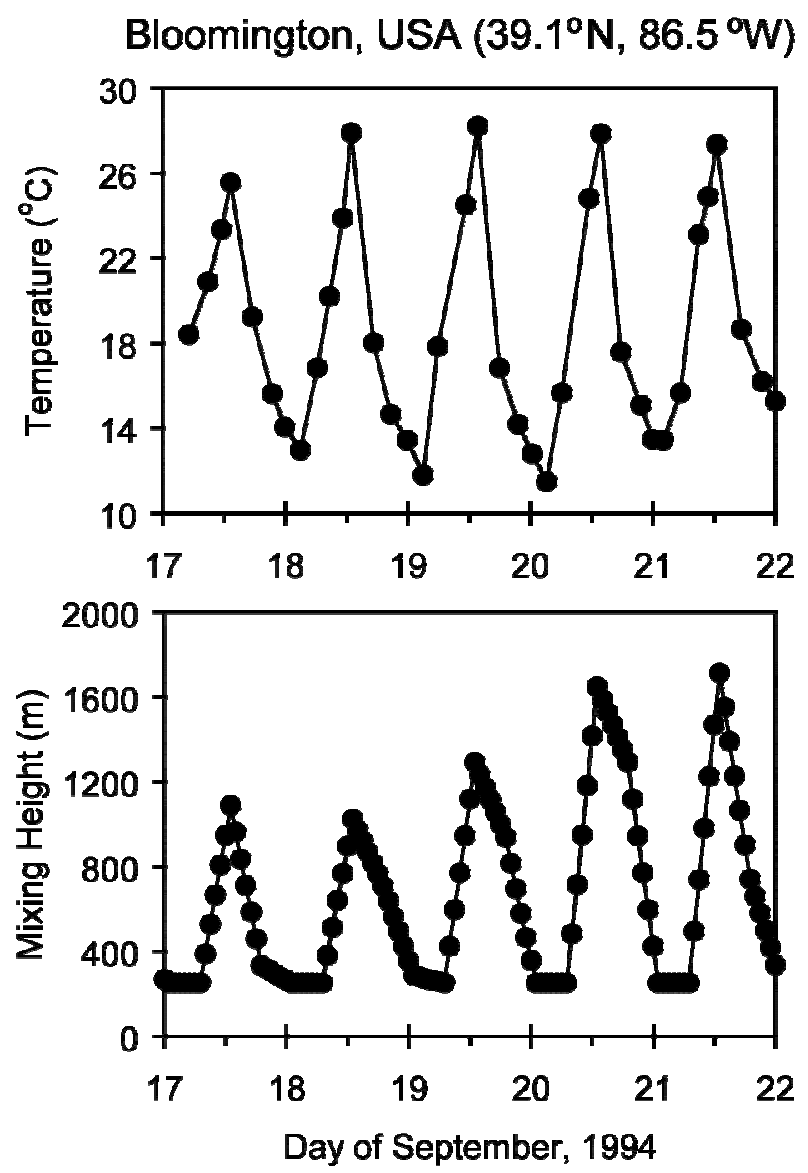

Figure S4: Diel variability in temperature (18) and atmospheric mixing height (17) at Bloomington, Indiana, USA in September 1994.

\subsection{Bidleman and Leone (19).}

Bidleman and Leone (19) interpreted concentrations of toxaphene measured in air and soil at agricultural sites in the southern United States. Toxaphene is a persistent, semi-volatile insecticide. Ratios of fugacity of toxaphene in soil to fugacity in air indicated a thermodynamic gradient that favored net volatilization from the soil to the air. The authors report monitoring data from several sites in Alabama, Louisiana and Texas during June of 1999 and 2000 where concentrations of toxaphene in air at night exceed those during the day. Exact sample dates and locations are not provided so it is not possible to extract mixing height data for each of the monitoring events described in the paper. However, Figure S5 shows variability in mixing height at a location in central Louisiana during June 1999 and 2000. 

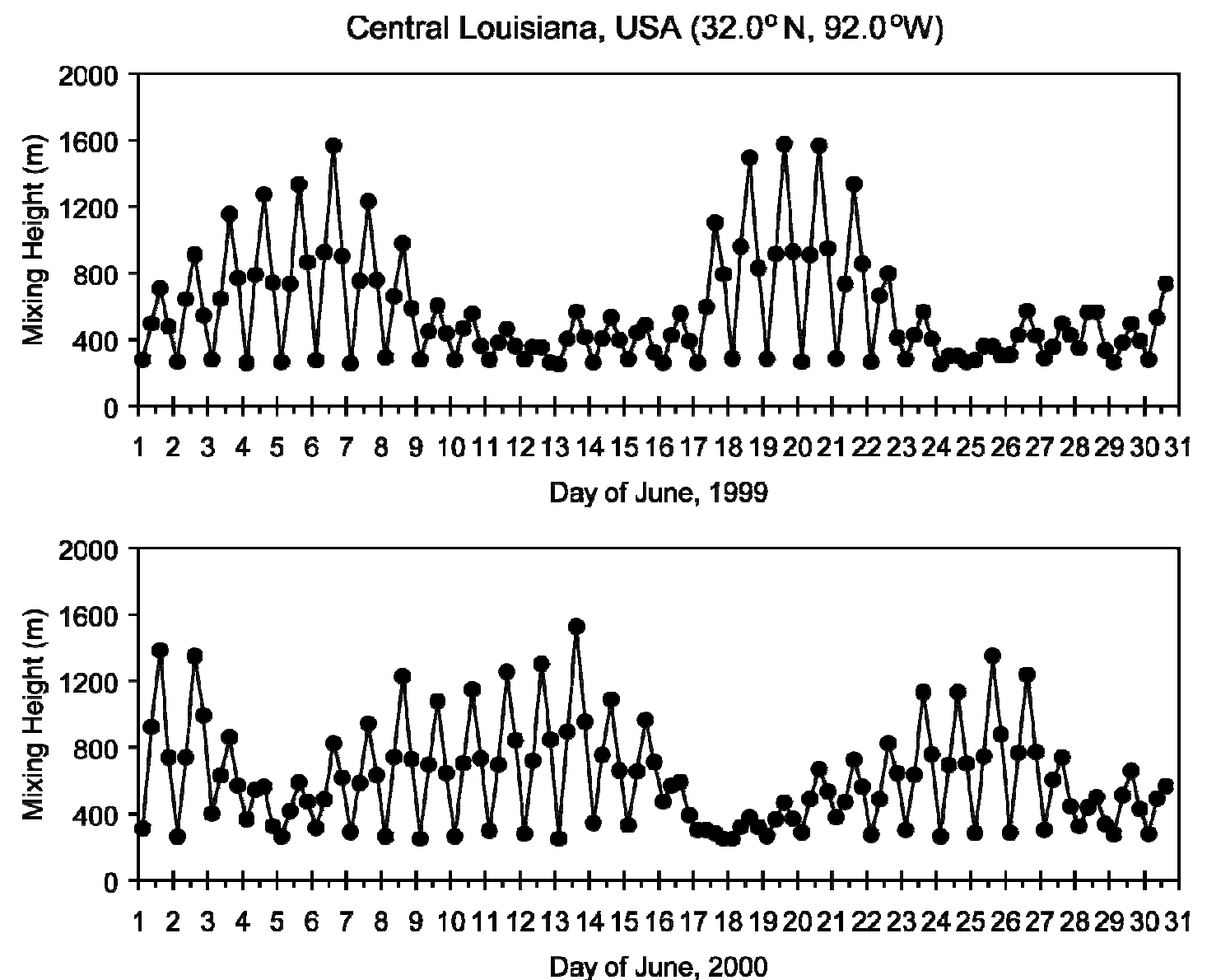

Figure S5: Variability in atmospheric mixing height in central Louisiana during June, 1999 and June 2000 (17).

Figure S5 shows several prolonged periods of stable diel variability in mixing height during June 1999 and June 2000. Toxaphene monitoring samples collected during periods of stable diel variability in mixing height would have source characteristics and atmospheric conditions analogous to conditions at Chicago, USA in July 1994, as described in the main text.

\subsection{Sofuoglu et al. (20).}

Sofuoglu et al. reported diel variability in concentrations of several organochlorine pesticides (OCPs) in air at a site near Izmir, Turkey in May of 2003 (20). The monitoring site was considered to be remote from possible sources of OCPs and therefore the source of contamination in the area is transport in air. Temperature 
varied with a regular diel pattern during the sampling campaign, with an amplitude of approximately $6^{\circ} \mathrm{C}$. Therefore temperature and source characteristics were similar to those reported at Hazelrigg, UK in the main text. However Sofuoglu et al. did not observe a regular diel pattern in OCPs in air except during the period between May 19 and 22. Figure S6 shows variability in measured concentration of $\beta$ hexachlorocyclohexane $(\beta-\mathrm{HCH})$, temperature and atmospheric mixing height at Izmir, Turkey during the sampling campaign. 

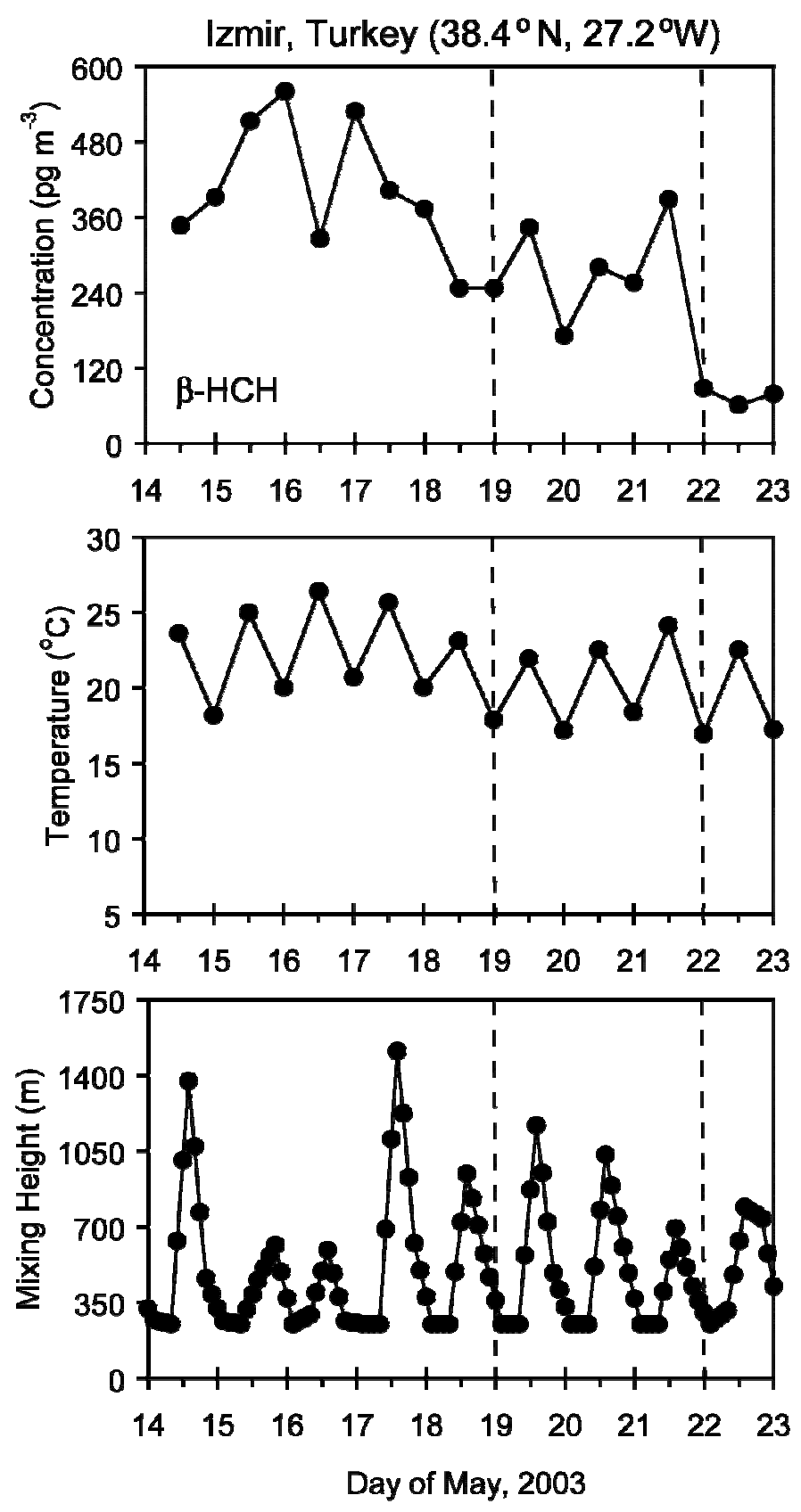

Figure S6: Concentration of beta-hexachlorcyclohexane $(\beta-\mathrm{HCH})$ in air $(20)$, temperature (20) and atmospheric mixing height (17) at Izmir, Turkey in May, 2003. Dashed lines encompass a period when temperature and atmospheric mixing height followed regular patterns and $\beta-\mathrm{HCH}$ concentrations were higher during the day than at night.

As shown in Figure S6, the period between May 18 and 21 was the only period of prolonged stable and repeating diel cycles in both temperature and atmospheric 
mixing height. This period corresponds with the only period when strong diel variability in OCP concentrations was observed by Sofuoglu et al. (20).

\subsection{Lohmann et al. (21).}

Lohmann et al. reported day-to-night variability in concentrations of chlorinated dibenzo- $p$-dioxins and furans from several sampling sites near Raritan Bay, New Jersey on July 5-12, 1998. Lohmann et al. did not observe a regular diel pattern in concentrations of the dioxins and furans in air, which is consistent with the temporal pattern in temperature and mixing height during the sampling campaign (Figure S7), which did not show a stable and repeating pattern. Lohmann et al. (21) discuss several possible factors that might influence the day-night variability in concentrations, and suggest that evolution of the boundary layer mixing height likely played an important role in determining the contaminant concentrations they measured. 
Raritan Bay, New Jersey $\left(40.5^{\circ} \mathrm{N}, 74.0^{\circ} \mathrm{W}\right)$
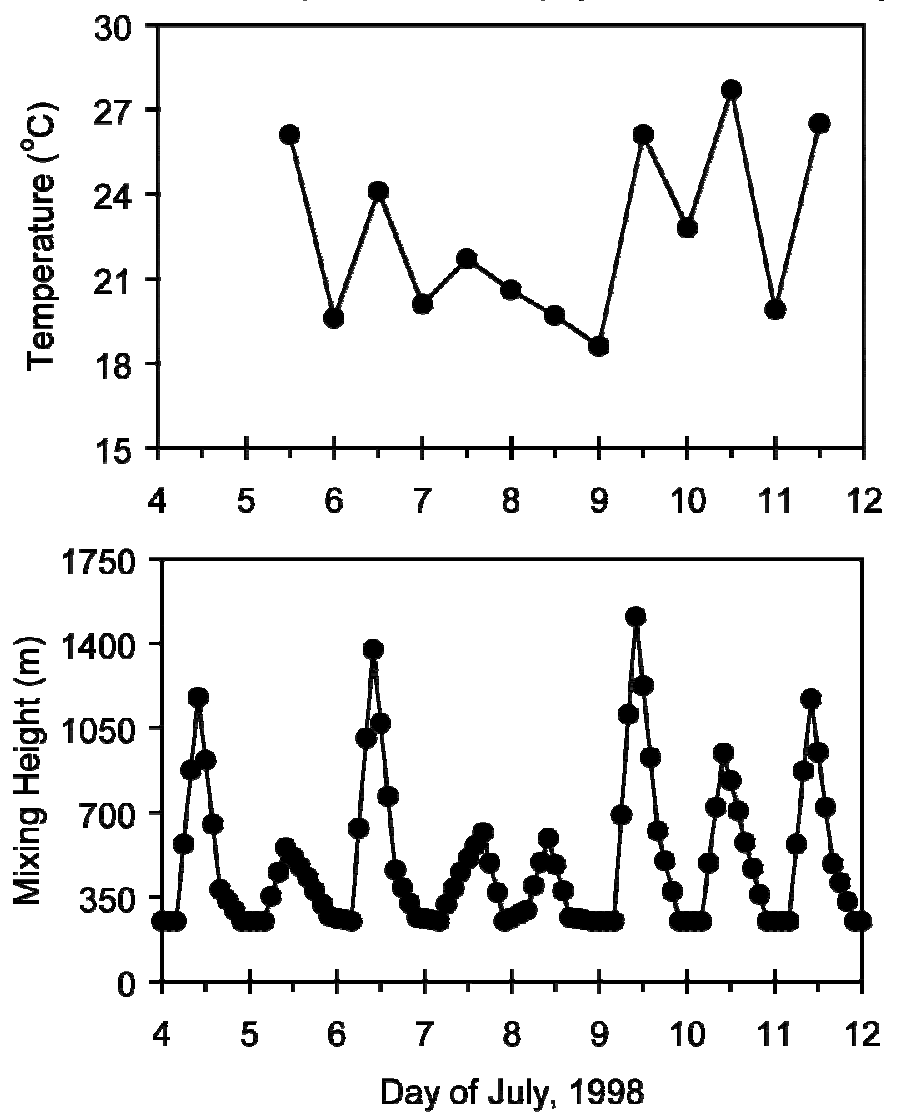

Figure S7: Temperature (21) and atmospheric mixing height (17) at Raritan Bay, New Jersey in July, 1998.

3. Additional Model Results for the Case Studies Presented in the Main Text.

The figures below show additional model results and data for the three primary case studies presented in the main text. Monitoring data for the entire sampling period of each study is included with results for additional PCB congeners. In some cases the monitoring period included some time when clear and repeating patterns in mixing height and temperature were not observed, and other factors were controlling variability in concentrations (for example, the last several data points from Hazelrigg, UK, and the first 24 hours of samples from Finokalia, Greece). 

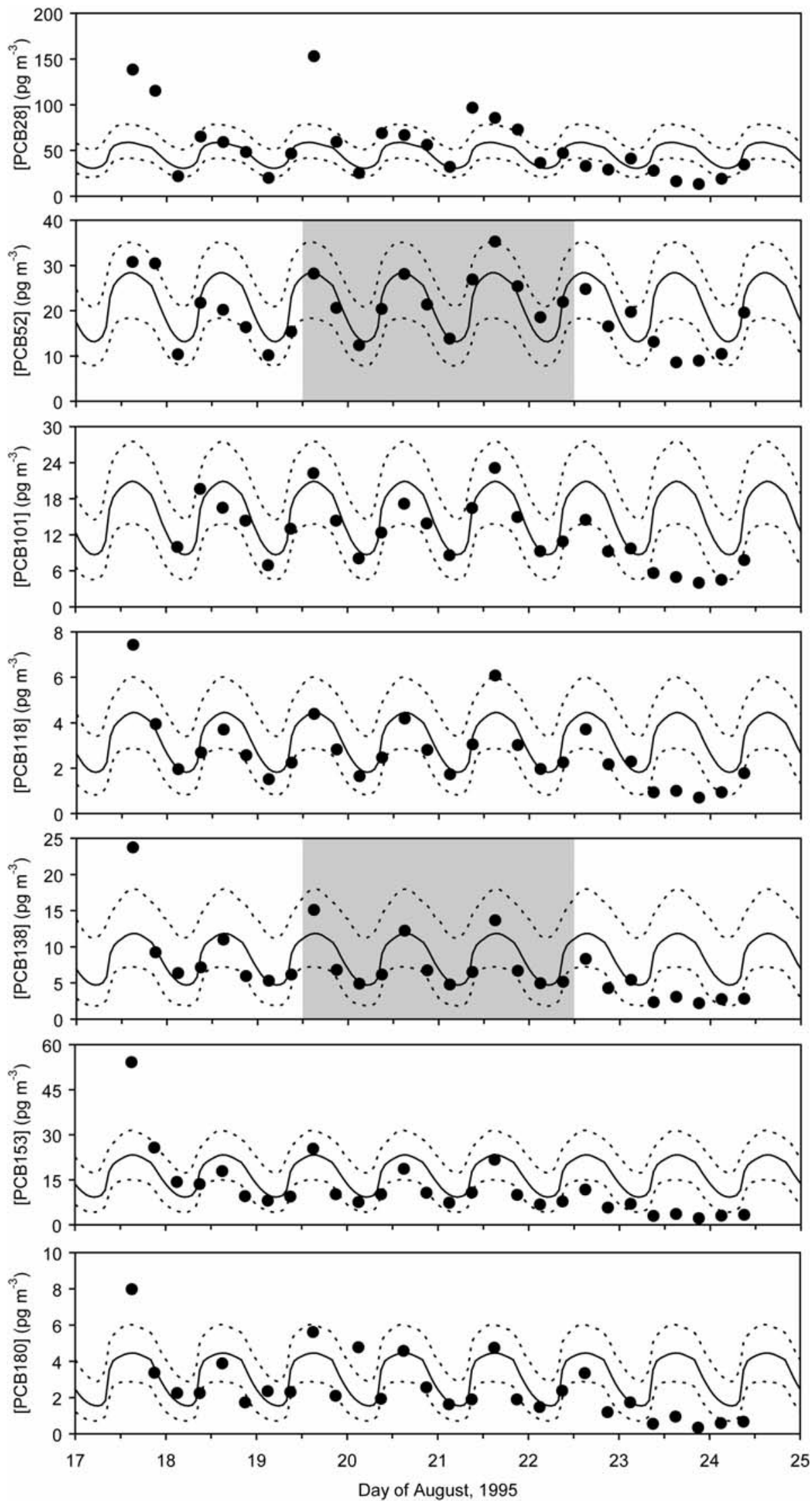

Figure S8: Additional monitoring data and model results for the Hazelrigg, UK case study (9). Shaded areas indicate data that is shown in Figure 2 of the main text. 

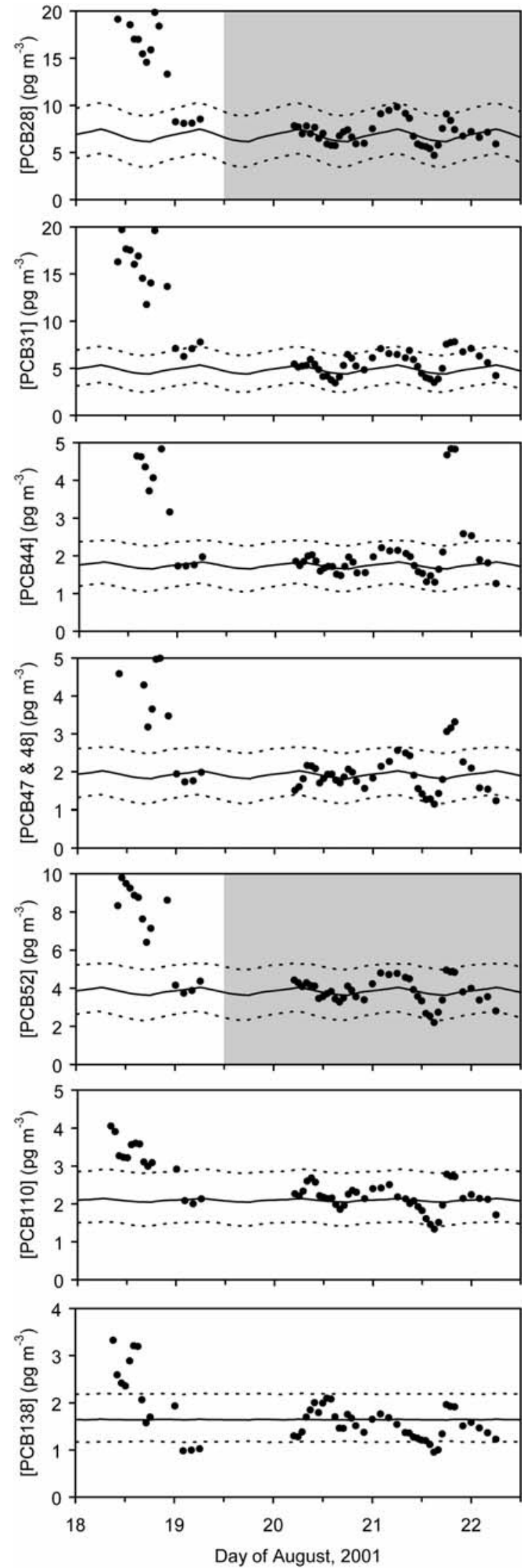

Figure S9: Additional monitoring data and model results for the Finokalia, Greece case study (22). Shaded areas indicate data that is shown in Figure 2 of the main text. 

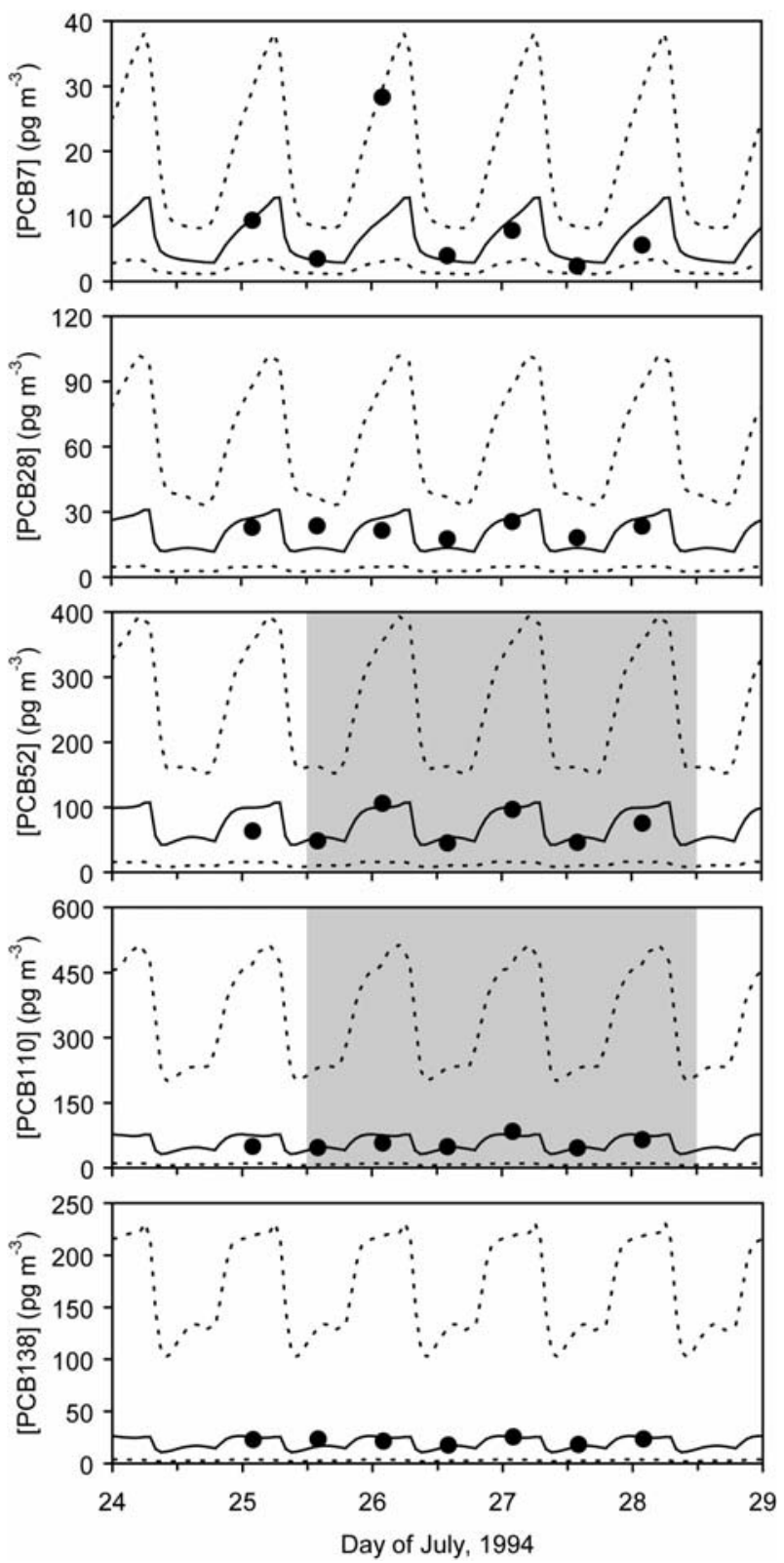

Figure S10: Additional monitoring data and model results for the Chicago, USA case study (23). Shaded areas indicate data that is shown in Figure 2 of the main text. 
4. References

(1) MacLeod, M.; Fraser, A. J.; Mackay, D., Evaluating and expressing the propagation of uncertainty in chemical fate and bioaccumulation models. Environ. Toxicol. Chem 2002 21, 700-709.

(2) Mackay, D. Multimedia environmental models: The fugacity approach. Lewis Publishers: Boca Raton, Florida, 2001.

(3) MacLeod, M.; Woodfine, D.; Brimacombe, J.; Toose, L.; Mackay, D., A dynamic mass budget for toxaphene in North America. Environ. Toxicol. Chem 2002 21, 1628-1637.

(4) MacLeod, M.; Mackay, D., Modeling transport and deposition of contaminants to ecosystems of concern: a case study for the Laurentian Great Lakes. Environmental Pollution 2004 128, 241-250.

(5) MacLeod, M.; Riley, W. J.; McKone, T. E. "Modeling transport and deposition of Level 1 substances to the Great Lakes.," 2005.

(6) MacLeod, M.; Riley, W. J.; McKone, T. E., Assessing the influence of climate variability on atmospheric concentrations of polychlorinated biphenyls using a global-scale mass balance model (BETR-global). Environ. Sci. Technol. 2005 39, 6749-6756.

(7) Cousins, I. T.; Mackay, D., Strategies for including vegetation compartments in multimedia models. Chemosphere 2001 44, 643-654.

(8) McLachlan, M. S.; Czub, G.; Wania, F., The influence of vertical sorbed phase transport on the fate of organic chemicals in surface soils. Environ. Sci. Technol. 2002 36, 4860-4867.

(9) Lee, R. G. M.; Hung, H.; Mackay, D.; Jones, K. C., Measurement and modeling of the diurnal cycling of atmospheric PCBs and PAHs. Environ. Sci. Technol. 1998 32, 2172-2179.

(10) Schenker, U.; MacLeod, M.; Scheringer, M.; Hungerbuhler, K., Improving data quality for environmental fate models: A least-squares adjustment procedure for harmonizing physicochemical properties of organic compounds. Environ. Sci. Technol. 2005 39, 8434-8441.

(11) Anderson, P. N.; Hites, R. A., OH radical reactions: The major removal pathway for polychlorinated biphenyls from the atmosphere. Environ. Sci. Technol. 1996 30, 1756-1763. 
(12) Mackay, D., Shiu, W.Y., Ma, K.C. Physical-Chemical Properties and Environmental Fate and Degradation Handbook CRC netBase CDROM: Boca Raton, Florida, USA, 1999.

(13) Wania, F.; Daly, G. L., Estimating the contribution of degradation in air and deposition to the deep sea to the global loss of PCBs. Atmospheric Environment 2002 36, 5581-5593.

(14) MacLeod, M.; Scheringer, M.; Hungerbuhler, K., Estimating enthalpy of vaporization from vapor pressure using Trouton's Rule. Environ. Sci. Technol. 2006 In Review.

(15) Beyer, A.; Wania, F.; Gouin, T.; Mackay, D.; Matthies, M., Selecting internally consistent physicochemical properties of organic compounds. Environmental Toxicology and Chemistry 2002 21, 941-953.

(16) Hornbuckle, K. C.; Eisenreich, S. J., Dynamics of gaseous semivolatile organic compounds in a terrestrial ecosystem - Effects of diurnal and seasonal climate variations. Atmospheric Environment 1996 30, 3935-3945.

(17) NCEP National Center for Environmental Prediction Global Reanalysis of Climate Data http://www.cpc.ncep.noaa.gov/products/wesley/reanalysis.html, 2005.

(18) Wallace, J. C.; Hites, R. A., Diurnal variations in atmospheric concentrations of polychlorinated biphenyls and endosulfan: Implications for sampling protocols. Environ. Sci. Technol. 1996 30, 444-446.

(19) Bidleman, T. E.; Leone, A., Soil-air relationships for toxaphene in the southern United States. Environmental Toxicology and Chemistry 2004 23, 23372342.

(20) Sofuoglu, A.; Cetin, E.; Bozacioglu, S. S.; Sener, G. D.; Odabasi, M., Short-term variation in ambient concentrations and gas/particle partitioning of organochlorine pesticides in Izmir, Turkey. Atmospheric Environment 2004 38, 44834493.

(21) Lohmann, R.; Brunciak, P. A.; Dachs, J.; Gigliotti, C. L.; Nelson, E.; Van Ry, D.; Glenn, T.; Eisenreich, S. J.; Jones, J. L.; Jones, K. C., Processes controlling diurnal variations of PCDD/Fs in the New Jersey coastal atmosphere. Atmospheric Environment 2003 37, 959-969. 
(22) Mandalakis, M.; Berresheim, H.; Stephanou, E. G., Direct evidence for destruction of polychlorobiphenyls by $\mathrm{OH}$ radicals in the subtropical troposphere.

Environ. Sci. Technol. 2003 37, 542-547.

(23) Totten, L. A.; Eisenreich, S. J.; Brunciak, P. A., Evidence for destruction of PCBs by the $\mathrm{OH}$ radical in urban atmospheres. Chemosphere 2002 47, 735-746. 